\title{
Development of prefabricated timber-concrete composite floor systems
}

1 Massimo Fragiacomo PhD

Associate Professor of Structural Design, Department of Architecture, Design and Urban Planning, University of Sassari, Alghero, Italy
2 Elzbieta Lukaszewska $\mathrm{PhD}$

Structural Engineer, SWECO AB, Stockholm, Sweden
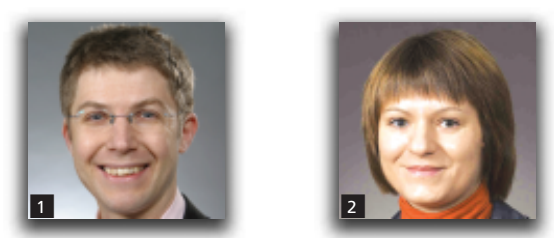

The timber-concrete composite structure consists of timber joists or beams effectively interconnected to a concrete slab cast on top of the timber members. This type of structure is finding new applications in multi-storey buildings and short-span bridges. Most of the research performed to date has focused on systems where 'wet' concrete is cast on top of timber beams with mounted connectors. This paper presents a novel composite system where the concrete slab is prefabricated off-site with connectors already embedded and then connected to the timber joists on site. The advantages of this method include reduced cost and better quality control of the materials, absence of 'wet' components on site during building erection and reduced concrete shrinkage effects on the composite beam. The paper reports an overview of a pilot research project conducted at Luleå University of Technology, Sweden, which includes direct shear tests to failure of different connection systems, bending tests to failure, dynamic (vibration) tests and long-term tests under sustained load of full-scale composite beams. The paper also reports the mechanical properties of the connection, which can be used within a simple design method given in Eurocode 5. The economic advantages of prefabrication and the possibility of demounting the structure make the proposed floor system very promising.

\section{Introduction}

Timber-concrete composite (TCC) systems are increasingly used for upgrading existing timber floors in residential/office buildings, as well as for buildings and bridges (Ceccotti, 1995). In the 1980s and 1990s, special attention was paid to multistorey timber buildings. For example, Natterer et al. (1996) proposed a composite system with a timber layer made of vertical nailed planks for the floors of new residential multistorey buildings.

In TCC structures, the concrete topping mainly resists compression, timber joists resist tension and bending, and the connection system transmits shear forces between the two components. Advantages of TCC over all-timber floors include increased loadcarrying capacity, higher stiffness (which leads to reduction in deflections and decreased susceptibility to vibrations), improved acoustic and thermal properties, and better fire resistance. Extensive research on TCC structures has been carried out on various types of shear connectors, used together with standard concrete and sawn timber/glued laminated beams or wooden decks. In most of the systems investigated, 'wet' concrete is cast on top of timber beams with mounted shear connector systems (traditional/wet TCC systems).

The connection system is a crucial part of any TCC system. The connection needs to be stiff and strong to maximise the composite action, but the number of connectors and the installation time should be minimal so as to make the system cost-effective (Deam et al., 2008). Evaluating the connection stiffness is important because the behaviour (static and dynamic) of the TCC structure is strongly influenced by the slip at the beam-to-slab interface (Gelfi et al., 2002), which requires consideration in the design. A method for calculating shear connector loads for mechanically jointed beams is given in annex B of Eurocode 5 Part 1-1 (CEN, 2003a) and the design of TCC connections is addressed in Eurocode 5 Part 2 (CEN, 2003b). In many cases, however, the load-carrying capacity and slip modulus of the connection have to be determined by experimental tests since Eurocode 5 only provides empirical formulae to calculate parameters of laterally loaded dowel-type fasteners inserted perpendicular to the shear plane (Blass and Schlager, 1997). 
The use of a concrete slab cast in situ as a component of a TCC structure has some disadvantages, notably:

(a) the introduction of a 'wet' component in the typically 'dry' construction processes applied in timber buildings

(b) the time needed for the concrete to set, which adds to the time required on site before the next scheduled action can be taken

(c) low stiffness and high creep while the concrete cures, which is particularly unfavourable for unpropped composite beams; these phenomena make propping of beams crucial to minimise permanent deflection and enable the development of sufficient initial composite stiffness to sustain the full selfweight of the concrete slab (Yeoh et al., 2009; 2010)

(d) the high cost of cast in situ concrete slabs mainly due to propping, transport of fresh concrete to site and the cost of the formwork

(e) potential problems of quality control.

Moreover, excessive shrinkage of concrete causes additional deflection and therefore low-shrinkage concrete is desirable in TCC structures to minimise any permanent deflection (Yeoh et al., 2009; 2010).

No previous research has explicitly focused on TCC systems in which 'dry-dry' shear connectors are embedded in the concrete slabs so that slabs and timber beams can be connected off site. Some previous attempts have been made to develop prefabricated composite systems (Bathon et al., 2006; Buchanan et al., 2008; Toratti and Kevarinmäki, 2001), but in these studies wet concrete was still cast on timber beams with inserted shear connectors.

The overarching purpose of the research project presented here was to explore the mechanical performance (static short and long term, and dynamic) of dry-dry shear connectors mounted in a prefabricated concrete slab in such a way that the concrete slab and glulam beams can be connected off site. Such a prefabricated TCC system can significantly reduce all the aforementioned drawbacks of wet systems. The main results from experimental static and dynamic (vibrations) tests and numerical analyses are presented in this paper.

\section{Basics of design}

The shear connectors are key elements of a composite system that require particular attention since they markedly affect the system's performance. There are two bounds of composite action:

(a) an upper bound of fully composite action, displayed by timber and concrete components that are rigidly connected with no interlayer slip, have cross-sections with a single neutral axis and identical flexural strains at the timberconcrete interface (Figure 1(a)); consequently, the transformed section method can be validly applied to analyse stresses in such systems

(b) a lower bound of fully non-composite action, displayed by

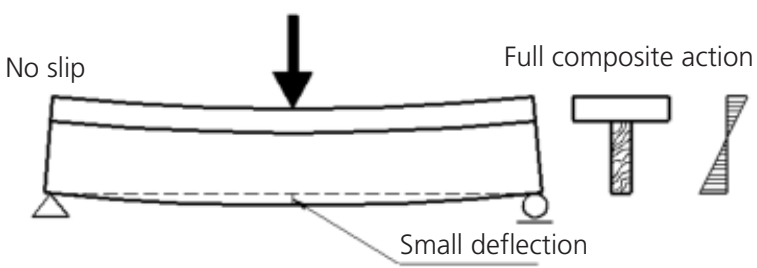

(a)

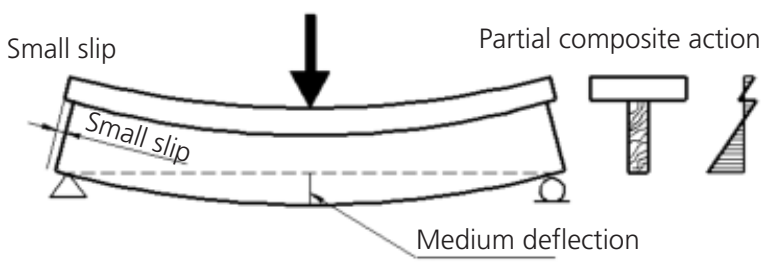

(b)

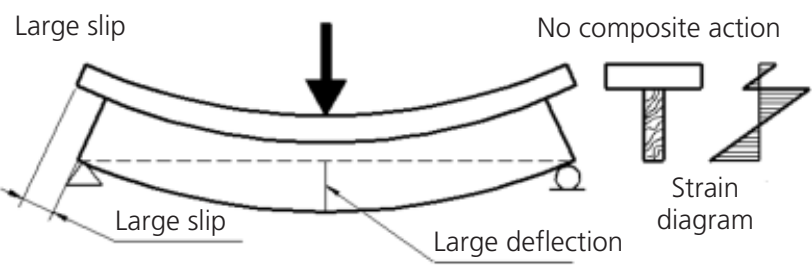

(c)

Figure 1. Strain diagrams for composite structures with (a) a rigid connection, (b) a deformable connection and (c) no connection between the timber beam and concrete slab

timber and concrete layers that are not connected and thus work independently, with no transfer of horizontal force between the two layers (Figure 1(c)); the layers have individual neutral axes and there is discontinuous flexural strain at the timber-concrete interface.

The timber and concrete layers are connected by mechanical fasteners in most cases (or by adhesives in a few cases). In reality, the shear connection system is deformable and most connectors generate at least some horizontal movement (slip) at the interface. Such behaviour is referred to as partial composite action. Figure 1(b) presents strain diagrams for structures with partial composite action.

The efficiency of the shear connection can be measured using the relationship suggested by Gutkowski et al. (2008)

1. Efficiency $=\frac{D_{\mathrm{N}}-D_{\mathrm{I}}}{D_{\mathrm{N}}-D_{\mathrm{C}}} \times 100$

where $D_{\mathrm{I}}, D_{\mathrm{N}}$ and $D_{\mathrm{C}}$ are the experimental deflection, the theoretical deflection in the absence of a connection and the theoretical deflection with a perfectly rigid connection between the concrete and timber, respectively. 
The design of TCC structures must satisfy both the ultimate limit state (ULS) and the serviceability limit state (SLS) in the short and long term. The ULS is checked by evaluating the maximum stresses in the component materials (timber, concrete and connection system) while the SLS is checked by evaluating the maximum deflection. In both cases, an elastic analysis is carried out. Annex B of Eurocode 5 Part 1-1 (CEN, 2003a) provides a simplified method for calculating these parameters of mechanically jointed beams (Figure 2) with flexible elastic connections, under the assumptions that:

(a) the beam is simply supported with a span $l$; for continuous beams, the expressions may be used with $l$ equal to $0 \cdot 8$ of the relevant span, and twice the cantilever length for cantilevered beams

(b) the individual parts (timber and concrete slab) are full length

(c) the individual parts are connected to each other by mechanical fasteners with a slip modulus $k$ and elastic behaviour

(d) the spacing $s$ between the fasteners is constant or varies uniformly according to the shear force, between $s_{\min }$ and $s_{\max }$ with $s_{\max } \leqslant 4 s_{\min }$

(e) the load acts in the $z$-direction, giving a moment $\boldsymbol{M}=\boldsymbol{M}(x)$ that varies sinusoidally or parabolically and a shear force $\boldsymbol{V}=\boldsymbol{V}(x)$.

This method is based on an approximate solution of the differential equation for beams with partial composite action. The simplified design method, the so-called $\gamma$-method, is closely related to the model initially derived by Möhler (1956) and has proved to provide excellent approximations for composite beams with closely spaced fasteners (Frangi and Fontana, 2003; Kenel, 2000).

According to the $\gamma$-method, the effective bending stiffness $(E I)_{\text {eff }}$ of a simply supported TCC beam is calculated as

$$
\text { 2. }(E I)_{\mathrm{eff}}=E_{1} I_{1}+\gamma E_{1} A_{1} a_{1}^{2}+E_{2} I_{2}+E_{2} A_{2} a_{2}^{2}
$$

The shear $\gamma$ coefficient and distances $a_{i}$ are given by

$$
\text { 3. } \gamma_{1}=\frac{1}{1+\left(\pi^{2} E_{1} A_{1} s / k L^{2}\right)}
$$

4. $a_{1}=\frac{h_{1}+h_{2}}{2}-a_{2}$

5. $\quad a_{2}=\frac{\gamma E_{1} A_{1}\left(h_{1}+h_{2}\right)}{2 \gamma E_{1} A_{1}+E_{2} A_{2}}$

where $I_{i}, A_{i}$ and $E_{i}$ designate the second moment of area, crosssectional area and modulus of elasticity of the concrete slab $(i=1)$ and timber beam $(i=2)$, respectively, $s$ is the connector spacing, $L$ is the beam length, $k$ is the slip modulus of the connector and the other variables are illustrated in Figure 2. $\gamma=0$ applies in cases where there is no connection system and the layers act fully independently, whereas $\gamma=1$ indicates full

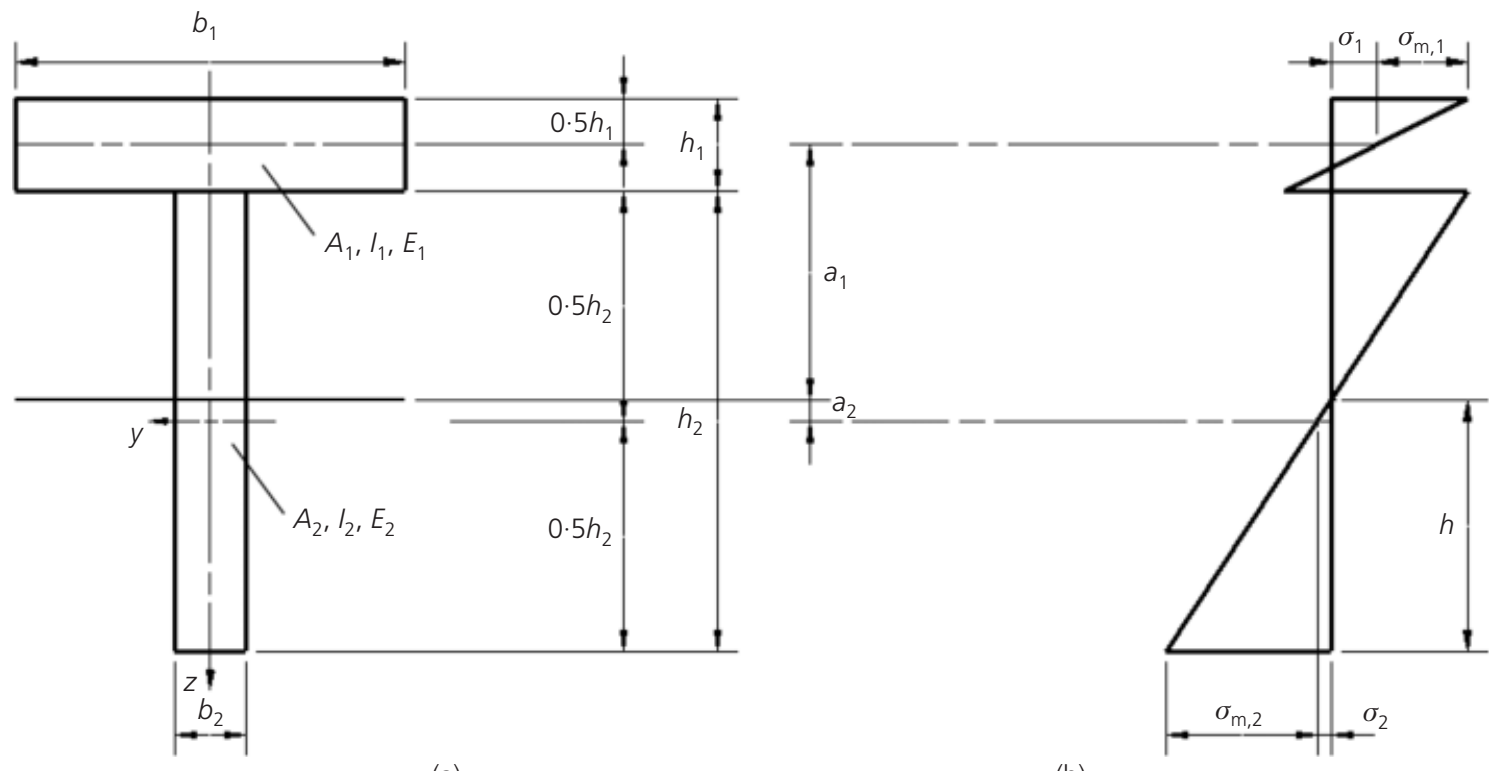

(a)

(b)

Figure 2. Cross-section (a) and stress distribution (b) of a composite beam with partial shear connection (Eurocode 5) 
composite action with no slip at the interface between the timber and concrete (see Figure 1).

The effective stiffness can be used to calculate the deflection, stress distribution and shear load in the fastener from

6. $\delta=\frac{5 \boldsymbol{q} L^{4}}{384(E I)_{\mathrm{eff}}}$ (for a simply supported beam)

7. $\sigma_{i}=\frac{\gamma E_{i} a_{i}}{(E I)_{\mathrm{eff}}} \boldsymbol{M}$

8. $\sigma_{m, i}=\frac{0 \cdot 5 E_{i} h_{i}}{(E I)_{\mathrm{eff}}} \boldsymbol{M}$

9. $\quad \boldsymbol{F}=\frac{\gamma E_{i} A_{i} a_{i} S}{(E I)_{\mathrm{eff}}} \boldsymbol{V}$

where $\delta$ is the mid-span deflection of a simply supported beam, $\boldsymbol{q}$ is the uniformly distributed load, $\sigma_{i}$ and $\sigma_{\mathrm{m}, i}$ are the stress at the centroid and the flexural component of the stress in the concrete $(i=1)$ and timber $(i=2)$, respectively, $\boldsymbol{F}$ is the shear load in the fastener, $\boldsymbol{M}$ is the bending moment and $\boldsymbol{V}$ is the shear force in the cross-section of interest.

The short-term verifications, at the initial state where loads are applied instantaneously and with no creep effect, can be carried out using the Young's moduli for concrete and timber, and the slip modulus of the connection, as described by Ceccotti (1995) and Ceccotti et al. (2002). Since the load-slip relationship of the shear connection is typically non-linear (Figure 3), two different slip moduli are considered for design purposes, as proposed by Ceccotti (1995): $k_{\mathrm{ser}}$ for SLS and $k_{\mathrm{u}}$ for the ULS.

The slip modulus $k_{\text {ser, }}$, which corresponds to the secant value at $40 \%$ of the load-carrying capacity of the connection $\left(k_{0 \cdot 4}\right)$, is usually evaluated by push-out tests according to EN 26891 (CEN, 1991). For the slip modulus $k_{\mathrm{u}}$, use of the secant value at $60 \%$ $\left(k_{0 \cdot 6}\right)$ is recommended (Figure 3 ). However, if experimental data are not available, Eurocode 5 Part 1-1 (CEN, 2003a) suggests using the formulae for timber-to-timber connections by multiplying the corresponding values of the slip modulus $k_{\text {ser }}$ by 2 . The slip modulus $k_{\mathrm{u}}$ may then be taken as $2 / 3$ of $k_{\text {ser }}$. Depending on the type of connection involved, this assumption may or may not be adequate. Ceccotti et al. (2007), for example, reported a significant $(50 \%)$ discrepancy between experimentally and analytically determined properties of connections, and recommended the use of empirically determined values of connection properties obtained from push-out tests.

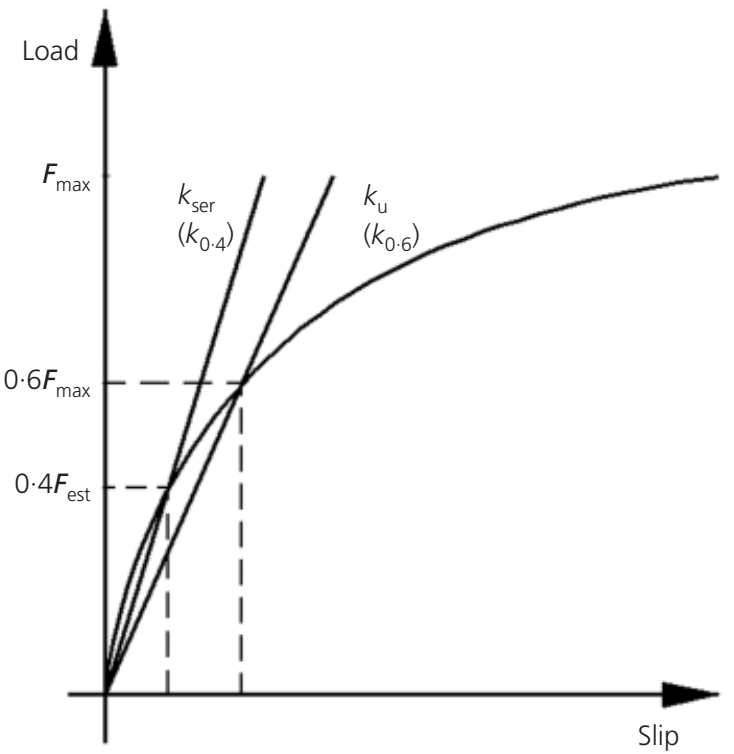

Figure 3. Example of load-slip behaviour of shear connector and definition of slip moduli: $k_{\text {ser }}\left(k_{0.4}\right)$ at $40 \%$ of the estimated loadcarrying capacity; $k_{\mathrm{u}}\left(k_{0 \cdot 6}\right)$ at $60 \%$ of the maximum load-carrying capacity of the connection

The verification of a composite beam in the long term is more problematic because concrete creep and shrinkage, creep and mechano-sorption of the timber and connection, and thermal strains of concrete and timber should all be considered. Numerical programs (Fragiacomo and Ceccotti, 2006a; Schänzlin, 2003) and analytical formulae (Fragiacomo, 2006; Fragiacomo and Ceccotti, 2006b; Schänzlin and Kuhlmann, 2004) have been proposed to provide accurate solutions. The simplified approach suggested by Ceccotti et al. (2002) does not account for shrinkage or thermal strains and, therefore, may lead to non-conservative solutions (Ceccotti et al., 2006; Fragiacomo, 2006; Fragiacomo et al., 2007). The simplified approach is based on the effective modulus method in which the creep and mechanosorption of the concrete, timber and connection are accounted for by reducing the elastic and slip moduli according to

10. $E_{1, \text { fin }}=\frac{E_{1}\left(t_{0}\right)}{1+\varphi\left(t, t_{0}\right)}$

11. $E_{2, \text { fin }}=\frac{E_{2, \text { mean }}}{1+k_{\text {def }, \mathrm{t}}}$

12. $k_{\mathrm{fin}}=\frac{k}{1+k_{\mathrm{def}, \mathrm{f}}}$ 
where $\phi\left(t, t_{0}\right)$ signifies the creep coefficient, $t$ and $t_{0}$ being the final and loading instants, $k_{\text {def,t }}$ and $k_{\text {def,f }}$ denote the creep coefficients of timber and connection, respectively.

The prefabricated TCC structures studied in this work were analysed at SLS and ULS using the $\gamma$-method. The corresponding outcomes of their short-term behaviour in terms of maximum mid-span deflection, maximum slip at the support, shear force in the maximally loaded connector and stresses in the glulam and concrete are presented elsewhere (Lukaszewska et al., 2007).

The design of prefabricated TCC beams according to the Eurocode 5 Part 1-1 (CEN, 2003a) can be carried out as suggested by Ceccotti (1995) and by Ceccotti et al. (2002). The flow diagram of the design process is summarised in Figure 4. The ULS of coupled tension and bending in the timber, shear in the timber, shear in the connection, and coupled compression and bending in the concrete slab must be checked both in the short and long term. For the short-term verifications, the actual Young's moduli of timber $E_{2 \text {,mean }}$ and concrete $E_{1}\left(t_{0}\right)$ and the slip modulus of the connection at ULS, $k_{\mathrm{u}}$, must be used in Equations 2-5 and 7-9. For the long-term verifications, the effects of the quasipermanent load combination must first be calculated so as to account for creep phenomena. The effective moduli of concrete, timber and connection as given by Equations 10-12 must be used

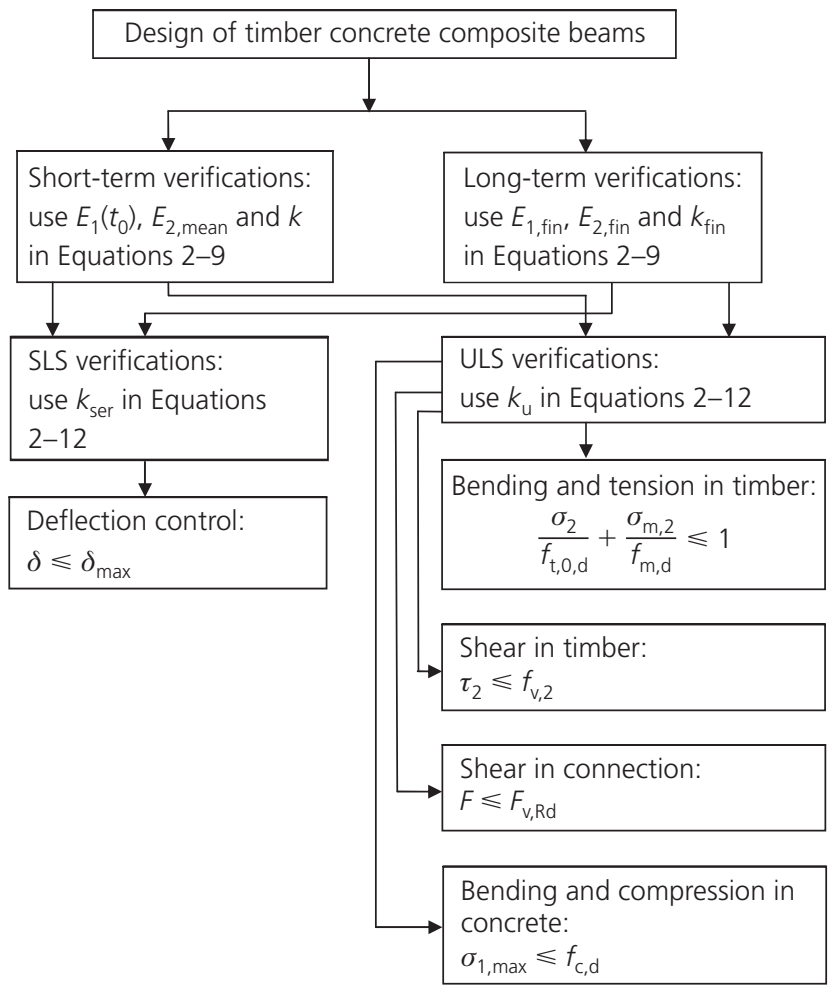

Figure 4. Flow diagram of the design process of prefabricated TCC beams in Equations 2-5 and 7-9. Then the effects of the difference between the ULS load condition and the quasi-permanent load condition are calculated using the actual elastic moduli of concrete, timber and connection in Equations 2-5 and 7-9. The solution in the long term is calculated by superimposing the effects due the quasi-permanent load condition on to the effects due to the difference between the ULS load condition and the quasi-permanent load condition. The SLS of maximum deflection must be controlled both in the short and long term. Unlike ULS verifications, the slip modulus at SLS, $k_{\text {ser }}$, must be used in Equations 2-6. Similarly to ULS verifications, the actual elastic moduli are to be used for verifications in the short term and the effective moduli have to be used to evaluate the effect of the quasi-permanent load condition in the long term. Unlike ULS verifications, however, the effects of the quasi-permanent load condition will be superimposed to the effect of the difference between the rare and the quasi-permanent load condition for verifications in the long term.

\section{Type of prefabricated shear connectors}

The shear connectors used for the prefabricated TCC systems are described by Lukaszewska et al. (2008). In this paper, the main focus is on the three shear connectors described in Table 1:

(a) SST $+\mathrm{S}^{*}$ - a long steel tube inserted into the concrete slab with one hexagon head coach screw (Figure 5(a))

(b) $\mathrm{SP}+\mathrm{N}^{*}-\mathrm{U}$-shaped steel plates welded to a long punched metal plate embedded into the slab and nailed to both sides of the glulam beam with annular ringed shank nails (Figure 5(b))

(c) $\mathrm{ST}+\mathrm{S}+\mathrm{N}-$ a long steel tube inserted into the concrete slab with one hexagon head coach screw and one notch cut from the glulam beam (Figure 5(c)).

These three connectors were selected with the help of a concrete prefabricator who provided technical expertise during the research project. The connectors were identified as the most suitable for prefabrication, being characterised by ease of production and therefore low cost.

To assess the mechanical properties and structural performance of the prefabricated TCC floor systems, five bending tests to failure were carried out on full-scale $(4.8 \mathrm{~m}$ long) specimens with $\mathrm{SST}+\mathrm{S}^{*}$ and $\mathrm{SP}+\mathrm{N}^{*}$ shear connectors at Luleå University of Technology, Sweden (Lukaszewska et al., 2010). The experimental and numerical results obtained using $\mathrm{SST}+\mathrm{S} *$ connectors are presented here. The SST $+\mathrm{S}^{*}$ connector type was selected for ease of implementation in the proposed prefabricated system even though it was neither the strongest nor the stiffest connector (Lukaszewska et al., 2008). Due to the excellent mechanical performance exhibited during shear tests, the $\mathrm{ST}+\mathrm{S}+\mathrm{N}$ connector was considered suitable for prefabricated TCC systems. Due to difficulties of manufacturing the full-scale concrete slab with these shear connectors in the laboratory, the ST $+\mathrm{S}+\mathrm{N}$ connector was not experimentally tested in full-scale beam speci- 
Type

$\mathrm{SST}+\mathrm{S}^{*}$

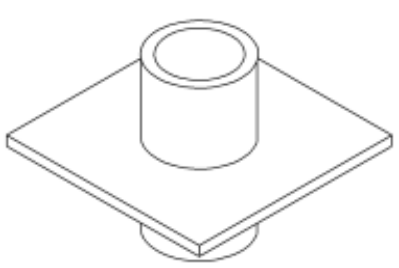

$\mathrm{SP}+\mathrm{N}^{*}$

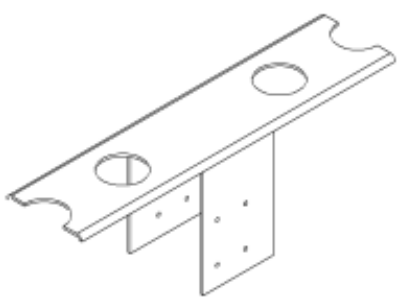

$\mathrm{ST}+\mathrm{S}+\mathrm{N}$

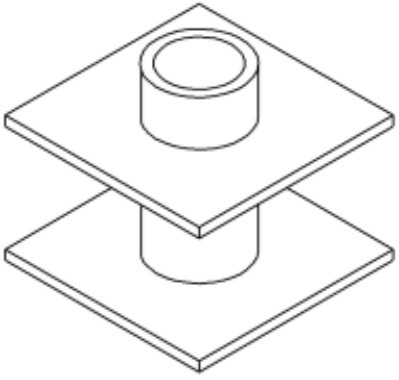

Description

$20 \mathrm{~mm}$ diameter, $47 \mathrm{~mm}$ long steel tube ( $3 \mathrm{~mm}$ thick) welded to a

$60 \times 60 \mathrm{~mm}$ steel plate ( $3 \mathrm{~mm}$ thick), inserted into the concrete slab with one $\varnothing 20 \times 160 \mathrm{~mm}$ hexagon head coach screw

U-shaped steel plates ( $3 \mathrm{~mm}$ thick) welded to a long punched metal plate ( $3 \mathrm{~mm}$ thick) embedded into the slab to a depth of $30 \mathrm{~mm}$ and nailed to both sides of the glulam beam with eight $\varnothing 4.5 \times 75 \mathrm{~mm}$ annular ringed shank nails

$20 \mathrm{~mm}$ diameter, $67 \mathrm{~mm}$ long steel tube ( $3 \mathrm{~mm}$ thick) welded to two $60 \times 60 \mathrm{~mm}$ steel plates ( $3 \mathrm{~mm}$ thick) inserted into the concrete slab with one $\varnothing 20 \times 160 \mathrm{~mm}$ hexagon head coach screw and one notch $(100 \mathrm{~mm}$ long, $25 \mathrm{~mm}$ deep) cut in the glulam beam

Table 1. Description of shear connectors

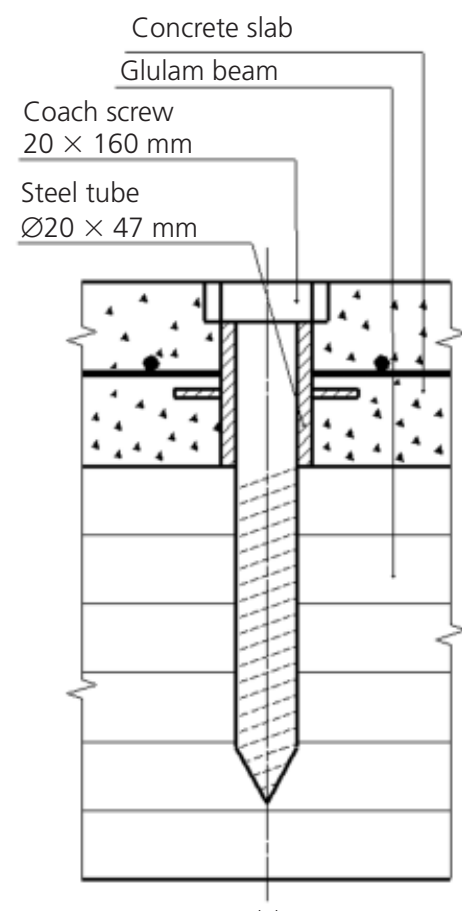

(a)

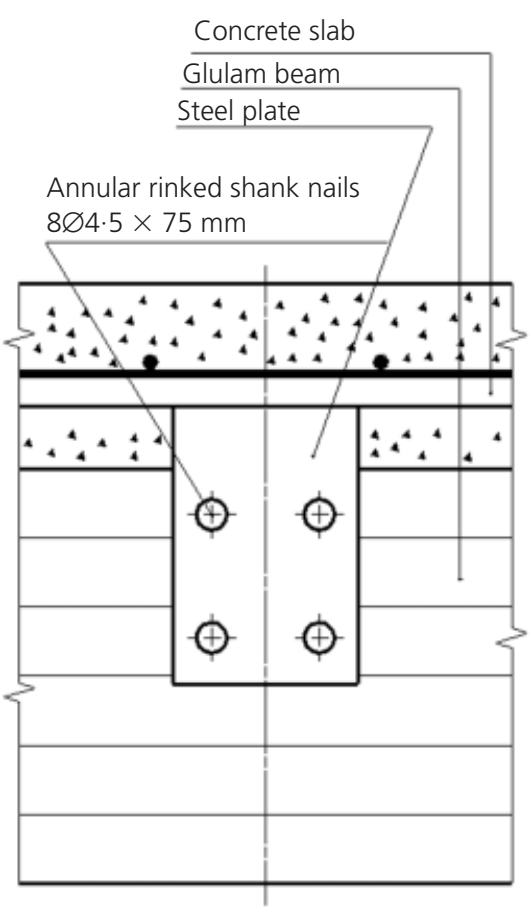

(b)

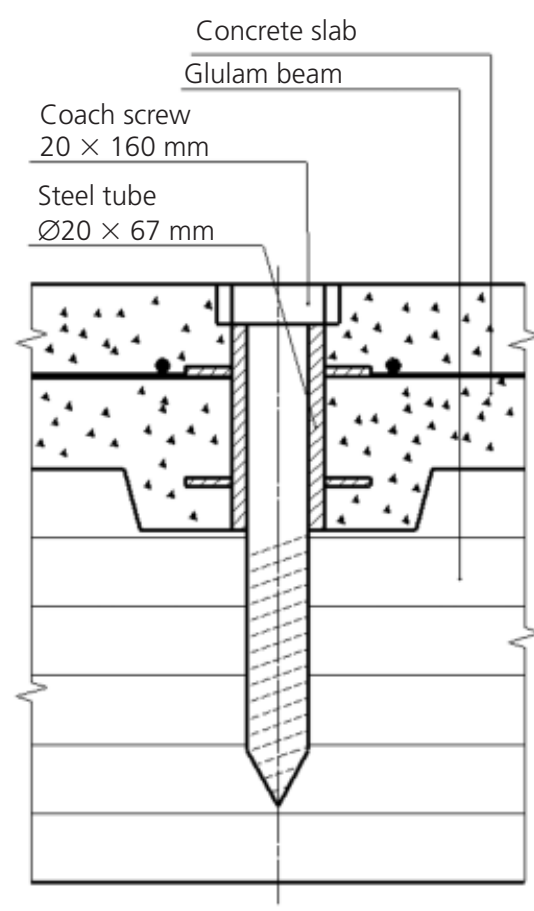

(c)

Figure 5. The types of connectors analysed in the present study:

(a) $S S T+\mathrm{S}^{*}$, (b) $\mathrm{SP}+\mathrm{N}^{*}$, (c) $\mathrm{ST}+\mathrm{S}+\mathrm{N}$ 
mens (Lukaszewska et al., 2008); however, mechanical short- and long-term performance was numerically predicted.

\subsection{Prefabrication of composite systems}

Two different specimens with pre-cast concrete slabs were produced. In both specimens, SST $+\mathrm{S}^{*}$ shear connectors (Figures 5-10) were used, the only difference between the two samples being the spacing of the connectors, which was varied from 250 to $500 \mathrm{~mm}$ centre-to-centre $(\mathrm{c} / \mathrm{c})$. Figure 6 shows the steel tubes in the moulding forms with custom-designed plastic caps inserted in each tube to make room for the screw head and keep the inner surface of the tube clear during concrete casting. The steel tubes were $3 \mathrm{~mm}$ thick with a $20 \mathrm{~mm}$ inner diameter. A $3 \mathrm{~mm}$ thick $60 \times 60 \mathrm{~mm}$ square plate was welded to each tube to improve anchorage of the connector in the concrete slab. The steel tubes were connected to the reinforcing steel mesh by spot welding and placed in the moulding form (Figure 6), ensuring correct

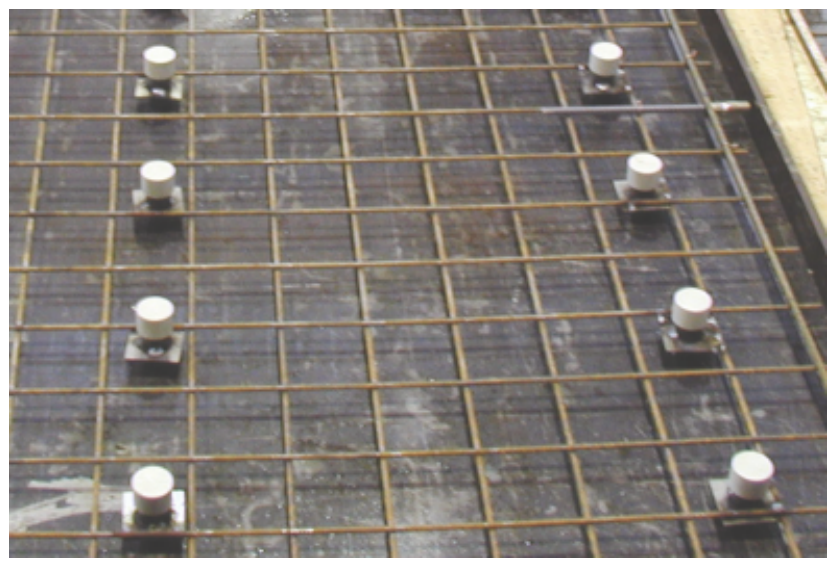

Figure 6. SST $+S^{*}$ type test specimen with connectors in the moulding form prior to concrete placement (step I)

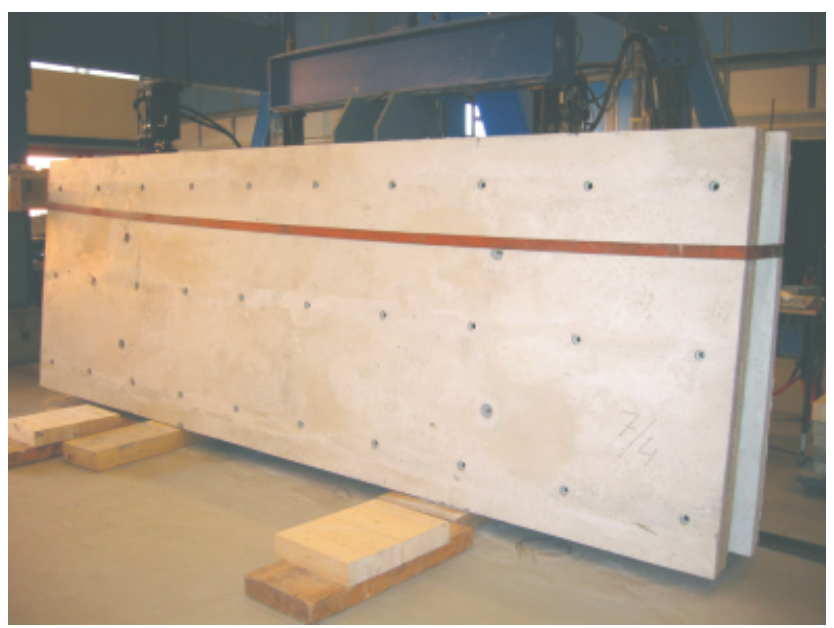

Figure 7. SST $+\mathrm{S}^{*}$ type test specimen with connectors after removal from the moulding form prior to assembly
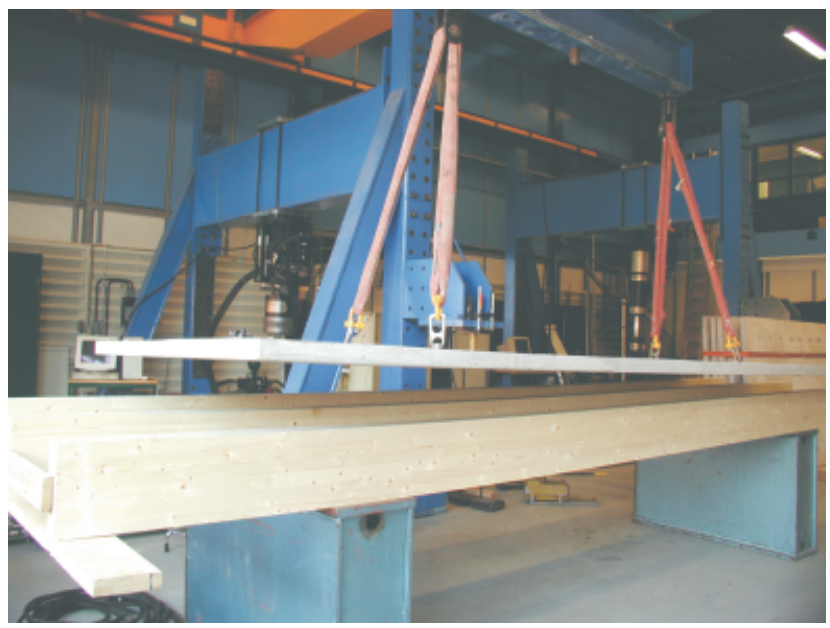

Figure 8. Test specimens with SST $+\mathrm{S}^{*}$ connectors during the assembly process (step II: placing the pre-cast concrete slab on top of glulam joists)

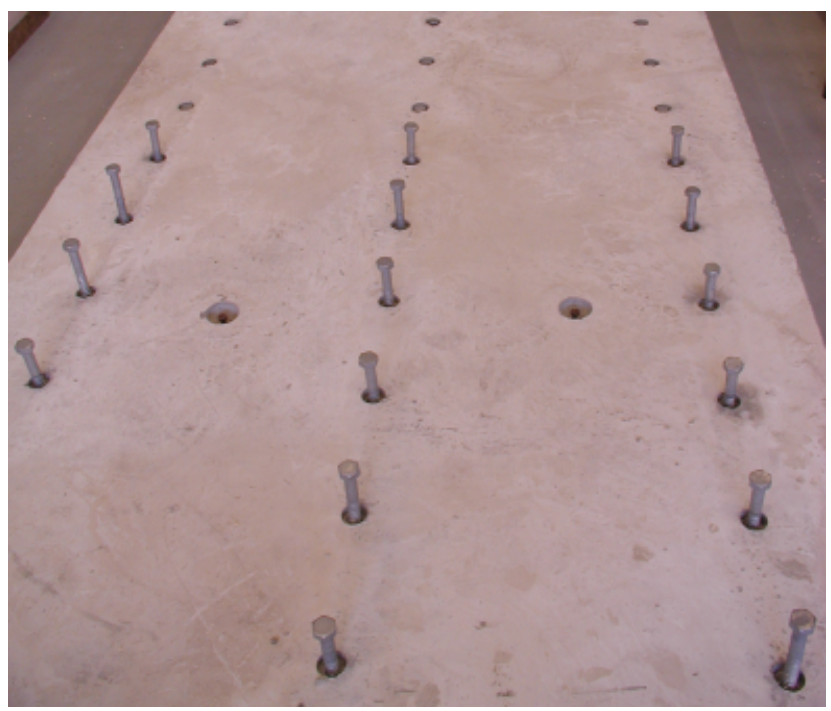

Figure 9. Pre-cast concrete slab with SST $+\mathrm{S}^{*}$ connectors during the assembly process (step III: screwing the concrete slab onto the glulam joists)

positioning of the connectors in both longitudinal and transversal directions. Figures 7-11 show a prefabricated concrete slab with embedded steel tubes during the assembly process.

The assembly time was fairly short compared, for example, with the time required to assemble systems with glued-in dowels or continuous connectors (Lukaszewska et al., 2008). Pre-drilling to $80 \%$ of the screw diameter was required prior to connecting the pre-cast concrete slab to the glulam beams. Coach screws were then inserted into the holes (Figure 9) and pre-tensioned with a 


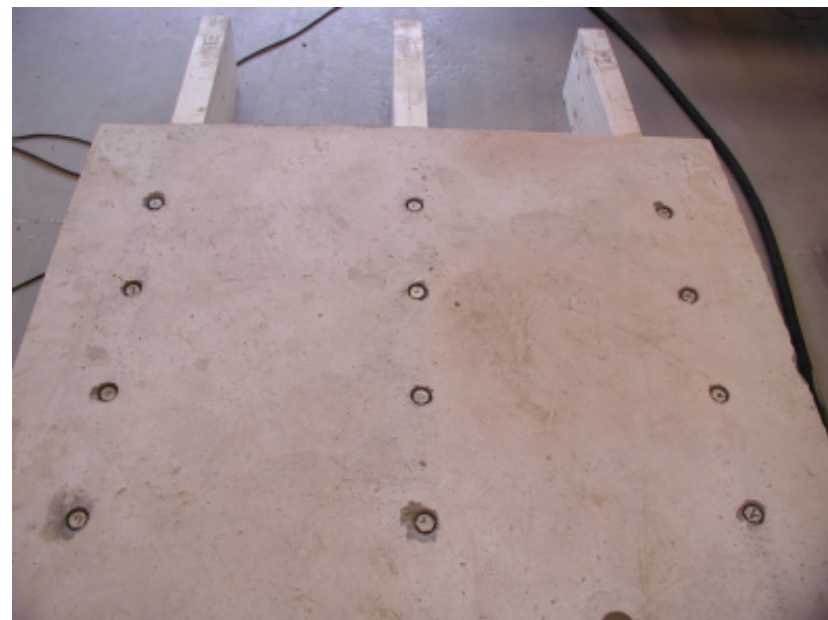

Figure 10. Pre-cast concrete slab with SST $+\mathrm{S}^{*}$ connectors after assembly (step IV: concrete slab screwed onto the glulam joists)

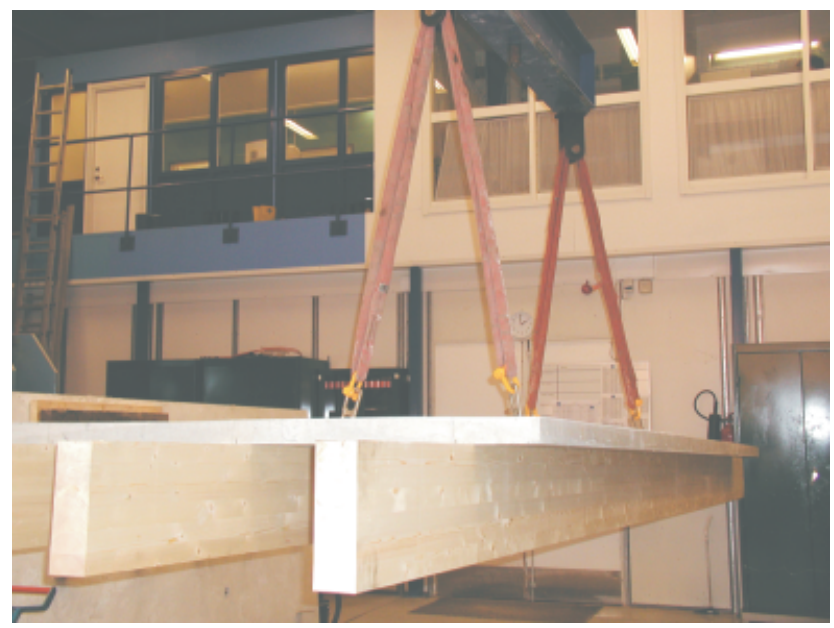

Figure 11. Prefabricated TCC floor strip with SST $+S^{*}$ type connectors ready after assembly

$130 \mathrm{Nm}$ torque moment using a torque wrench. Figures 10 and 11 show a prefabricated TCC floor strip with SST $+\mathrm{S}^{*}$ type connectors.

\section{Experimental programme}

4.1 Short-term shear and bending tests

A detailed description of the shear tests to failure performed on the connectors presented in Table 1 is given by Lukaszewska et al. (2008). After the shear tests, three full-scale bending tests were performed on specimens with SST $+\mathrm{S}^{*}$ shear connectors to investigate the structural performance of the composite beams. The specimens comprised a $60 \times 1600 \times 4800 \mathrm{~mm}$ prefabricated concrete slab and three $90 \times 270 \times 4800 \mathrm{~mm}$ glulam joists (Figure 12). The beam specimens were loaded to failure over a

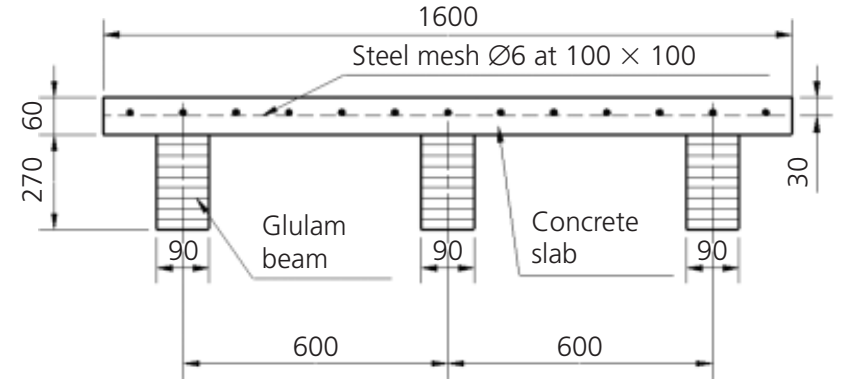

Figure 12. Cross-section of composite beams tested (dimensions in $\mathrm{mm}$ )

$4440 \mathrm{~mm}$ span in four-point bending tests. A full description of the bending test experimental programme is presented by Lukaszewska et al. (2010).

\subsection{Dynamic tests}

The purpose of the dynamic tests was to investigate the natural frequencies and damping ratios of the prefabricated TCC systems, which represent the system's behaviour at SLS. Five impact tests with five repetitions each were conducted on the specimen with $\mathrm{SST}+\mathrm{S}^{*}$ (tests $1 \mathrm{a}-5 \mathrm{a}$ ) connectors spaced at $250 \mathrm{~mm}$ c/c (Figure 11). It should be noted that the results are only comparative because the test specimens represent a strip of an entire floor; the transverse stiffness, which significantly affects the response of floor systems, will increase for a whole floor.

The concrete slab of the specimen was struck on its longer edges with a $5 \mathrm{~kg}$ hammer at $1 \mathrm{~m}$ from the shorter edge. The resulting vertical accelerations were then recorded using two solid state accelerometers. The first accelerometer was always located at a point located at $1 / 3$ of the specimen's width and half the specimen's length away from its support, while the second accelerometer was located at $1 / 3$ of the specimen's width and 1110, 740, 555, 444 and $370 \mathrm{~mm}$ away from the specimen's support in tests $1 \mathrm{a}-5 \mathrm{a}$, respectively. The acceleration records were used to estimate the natural frequencies and damping ratios for the floor specimens. Table 2 summarises the impact test programme. In the same way, the Impact test Accelerometer position (distance measured number from specimen support): $\mathrm{mm}$

\section{Accelerometer $1 \quad$ Accelerometer 2}

\begin{tabular}{lrr}
\hline $1 a$ & 2220 & 1110 \\
$2 a$ & 2220 & 740 \\
$3 a$ & 2220 & 555 \\
$4 a$ & 2220 & 444 \\
$5 a$ & 2220 & 370
\end{tabular}

Table 2. Impact test programme for specimen with SST + S* connector type 
impact test was also performed on a specimen with $\mathrm{SP}+\mathrm{N}^{*}$ type connectors spaced at $600 \mathrm{~mm} \mathrm{c} / \mathrm{c}$.

\subsection{Long-term bending tests}

The purpose of the long-term tests was to investigate the timedependent behaviour of the prefabricated TCC systems at SLS. Two $4.8 \mathrm{~m}$ long beam specimens, representative of floor strips, were constructed and tested under sustained loading for 1 year. A detailed description of test preparations and results is given by Lukaszewska et al. (2009). Only the results for SST $+\mathrm{S}^{*}$ connectors are presented here. The beam specimen comprised a $60 \times 800 \times 4800 \mathrm{~mm}$ prefabricated concrete slab and one $90 \times 270 \times 4800 \mathrm{~mm}$ glulam joist.

Two concentrated loads $(6.65 \mathrm{kN}$ each) were applied at the third points of the $4440 \mathrm{~mm}$ beam span. These values were calculated as the quasi-permanent part of the service load, corresponding to $13 \%$ of the experimental collapse load determined during the tests to failure. The point loads were left on the specimens for 339 days, during which deflections, slips, strains and environmental conditions (temperature and relative humidity) were measured. After the point loads were removed, monitoring continued for another 21 days in order to investigate the elastic recovery of the specimens.

\section{Test results}

\subsection{Shear}

A full description of the shear test results for all the tested connectors in terms of shear forces versus slip is given by Lukaszewska et al. (2008). The shear force-relative slip curves for the three connectors of interest (Table 1 and Figure 5) are presented in Figure 13, which also shows analytical approximations useful to represent the connectors' behaviour while modelling the TCC beam using commercial or customised software

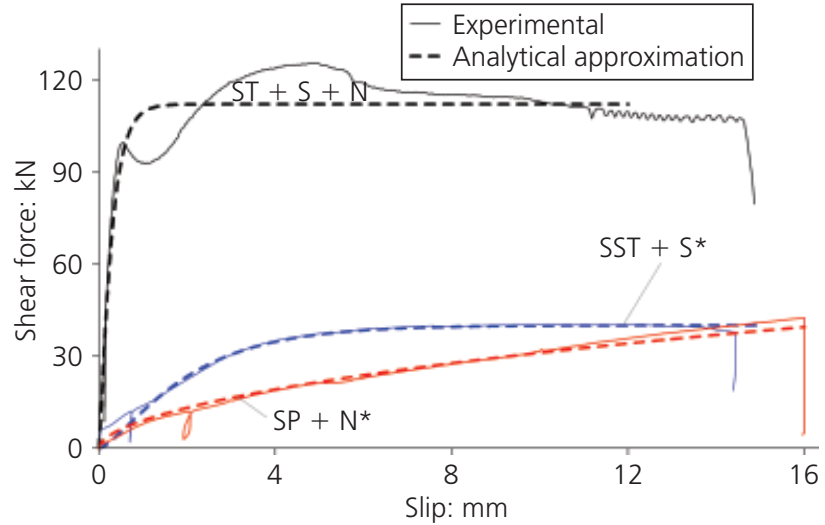

Figure 13. Shear test results for the three connection types

packages. The values in bold font in Table 3 were used in the design of the prefabricated TCC beams $\left(k_{0.4}\right.$ for SLS verifications, and $k_{0.6}$ and $\boldsymbol{F}_{\max }$ for ULS verification, as described in Section 2). The 5th percentiles of the shear strength, which are needed for design of connections at ULS, represent only a conservative estimate as few samples were tested to failure. The values in italic $(\sigma)$ represent standard deviation.

\subsection{Bending tests}

Comparisons of experimental, analytical and numerical values of mid-span deflection, slip and shear force at the first connector, stresses in the top fibre of concrete and in the bottom fibre of glulam are shown in Table 4 (based on Eurocode 5 design guidelines) for the beam with $\mathrm{SST}+\mathrm{S}^{*}$ connectors spaced at $250 \mathrm{~mm} \mathrm{c/c}$ (analytical, experimental and numerical comparisons for other shear connectors can be found in Lukaszewska et al. (2007)). The numerical predictions were obtained using a uniaxial finite-element (FE) model for non-linear analyses of TCC beams

\begin{tabular}{|c|c|c|c|c|c|c|}
\hline \multicolumn{2}{|c|}{ Type of connection } & \multicolumn{3}{|c|}{ Slip moduli } & \multirow{2}{*}{$\begin{array}{c}\text { Shear strength, } \\
F_{\text {max }}: k N\end{array}$} & \multirow{2}{*}{$\begin{array}{l}\text { Max. slip, } \\
\text { s: mm }\end{array}$} \\
\hline & & $k_{0.4}: \mathrm{kN} / \mathrm{mm}$ & $k_{0.6}: \mathrm{kN} / \mathrm{mm}$ & $k_{0.8}: \mathrm{kN} / \mathrm{mm}$ & & \\
\hline \multirow{4}{*}{$\begin{array}{l}\text { SST + S* } \\
\text { (4 samples) }\end{array}$} & Range & $5 \cdot 9-12 \cdot 8$ & $7 \cdot 0-10 \cdot 2$ & $6 \cdot 6-9 \cdot 3$ & $36 \cdot 5-41 \cdot 3$ & $15 \cdot 0$ \\
\hline & Average & 8.5 & $8 \cdot 3$ & $7 \cdot 4$ & $38 \cdot 2$ & \\
\hline & $\sigma$ & $3 \cdot 0$ & 1.4 & $1 \cdot 3$ & $3 \cdot 0$ & \\
\hline & 5th percentile & - & - & - & $35 \cdot 1$ & \\
\hline \multirow{4}{*}{$\begin{array}{l}\mathrm{SP}+\mathrm{N}^{*} \\
\text { (2 samples) }\end{array}$} & Range & $5 \cdot 0-5 \cdot 7$ & $3 \cdot 1-3 \cdot 5$ & $2 \cdot 4-3 \cdot 0$ & $37 \cdot 0-43 \cdot 0$ & $16 \cdot 0$ \\
\hline & Average & $5 \cdot 3$ & $3 \cdot 3$ & $2 \cdot 7$ & $40 \cdot 0$ & \\
\hline & $\sigma$ & 0.5 & $0 \cdot 3$ & $0 \cdot 4$ & $4 \cdot 3$ & \\
\hline & 5th percentile & - & - & - & $37 \cdot 3$ & \\
\hline \multirow{4}{*}{$\begin{array}{l}\mathrm{ST}+\mathrm{S}+\mathrm{N} \\
\text { (3 samples) }\end{array}$} & Range & $221 \cdot 3-245 \cdot 6$ & $231 \cdot 6-248 \cdot 2$ & $139 \cdot 6-217 \cdot 9$ & $99 \cdot 6-126 \cdot 7$ & $12 \cdot 0$ \\
\hline & Average & $235 \cdot 7$ & $234 \cdot 4$ & $178 \cdot 0$ & $110 \cdot 6$ & \\
\hline & $\sigma$ & $12 \cdot 8$ & 8.7 & $39 \cdot 2$ & $14 \cdot 2$ & \\
\hline & 5th percentile & - & - & - & $100 \cdot 2$ & \\
\hline
\end{tabular}

In bold: values of slip moduli and shear strength used in design of timber-concrete composite beams

Table 3. Shear test results for the different connectors 


\begin{tabular}{|c|c|c|c|c|c|c|c|c|c|c|c|c|}
\hline & \multicolumn{6}{|c|}{ SLS load $=92.04 \mathrm{kN}$} & \multicolumn{6}{|c|}{ ULS load $=138.06 \mathrm{kN}$} \\
\hline & Exp. & Num. & $\begin{array}{l}\text { Analyt. } \\
k_{0 \cdot 4 \exp }\end{array}$ & Error: \% & $\begin{array}{l}\text { Analyt. } \\
k_{0 \cdot 4 \mathrm{EC} 5}\end{array}$ & Error: \% & Exp. & Num. & $\begin{array}{l}\text { Analyt. } \\
k_{0 \cdot 6 \exp }\end{array}$ & Error: \% & $\begin{array}{l}\text { Analyt. } \\
k_{0.6 \mathrm{EC} 5}\end{array}$ & Error: \% \\
\hline$v_{\max }: \mathrm{mm}$ & $14 \cdot 41$ & 14.90 & 14.44 & 0.2 & $12 \cdot 19$ & $-15 \cdot 4$ & $21 \cdot 74$ & $22 \cdot 14$ & $21 \cdot 82$ & 0.4 & $20 \cdot 91$ & $-3 \cdot 8$ \\
\hline$s_{\max }: m m$ & 1.23 & $1 \cdot 34$ & $1 \cdot 18$ & $-4 \cdot 1$ & $1 \cdot 26$ & $2 \cdot 4$ & 1.89 & 1.98 & 1.76 & $-6 \cdot 9$ & 1.63 & $-13 \cdot 8$ \\
\hline$F_{\text {conn }}: \mathrm{kN}$ & - & $10 \cdot 40$ & $9 \cdot 38$ & $-9 \cdot 8$ & 11.92 & $14 \cdot 6$ & - & $15 \cdot 89$ & $14 \cdot 61$ & $-8 \cdot 1$ & $15 \cdot 44$ & $-2 \cdot 8$ \\
\hline$\sigma_{\text {glulam }}: \mathrm{MPa}$ & - & $12 \cdot 44$ & $12 \cdot 34$ & -0.8 & $11 \cdot 29$ & $-9 \cdot 2$ & - & $18 \cdot 60$ & $18 \cdot 57$ & $-0 \cdot 2$ & $18 \cdot 15$ & $-2 \cdot 4$ \\
\hline$\sigma_{\text {concrete }}: \mathrm{MPa}$ & - & 8.47 & $7 \cdot 81$ & $-7 \cdot 8$ & $7 \cdot 19$ & $-15 \cdot 1$ & - & 12.06 & 11.76 & $-2 \cdot 5$ & $11 \cdot 29$ & $-6 \cdot 4$ \\
\hline
\end{tabular}

c/c (error \% of analytical values calculated with respect to bold values)

Table 4. Comparison of analytical, experimental and numerical values obtained for different variables for the beam with SST $+S^{*}$ connectors spaced at $250 \mathrm{~mm}$

(Fragiacomo et al., 2004, Fragiacomo and Ceccotti 2006a). In the analyses, the analytical approximation of the shear force-relative slip relationship displayed in Figure 13 was used. The analytical predictions were obtained using the approach described in Section 2 with two different hypotheses:

(a) using the mean experimental values of the slip moduli $k_{0 \cdot 4 \exp }$ and $k_{0 \cdot 6 \exp }$

(b) using the values of $k_{0 \cdot 4 \mathrm{EC} 5}$ and $k_{0 \cdot 6 \mathrm{EC} 5}$ calculated by applying the analytical formulae proposed in Eurocode 5 (CEN, 2003a).

The significantly larger errors obtained when the Eurocode 5 formulae are used suggests the opportunity always to use experimental values of the connection slip modulus measured in shear tests. The use of the analytical approach with experimentally determined shear moduli $\left(k_{0 \cdot 4 \exp }\right.$ and $\left.k_{0 \cdot 6 \exp }\right)$ leads to accurate results since the differences with respect to the numerical and, where available, experimental values do not exceed $10 \%$ for both SLS and ULS load levels. As shown in Table 4, larger errors were detected for the slip and shear forces in the connection; this is in accordance with the theory presented in annex B of Eurocode 5 Part 1-1 (CEN, 2003a) where the sinusoidal approximation of the vertical load is generally fairly good for the deflection and bending moments, but may lead to larger errors for the slip and shear forces.

The numerical solutions were found to be very close to the experimental values (Figure 14) and were thus used to predict the quantities that were not measured during the experimental tests: the maximum shear force in the connection $\boldsymbol{F}_{\text {conn }}$ and the maximum stress at the bottom fibre of the glulam beam $\sigma_{\text {glulam }}$ and top fibre of the concrete slab $\sigma_{\text {concrete }}$ (Table 4).

Table 5 presents experimental and numerical results of the tests to failure performed on specimens with SST $+\mathrm{S}^{*}$ shear connectors and connection efficiencies $E$ at SLS and ULS load levels, as determined from Equation 1 (Gutkowski et al., 2008). The out-

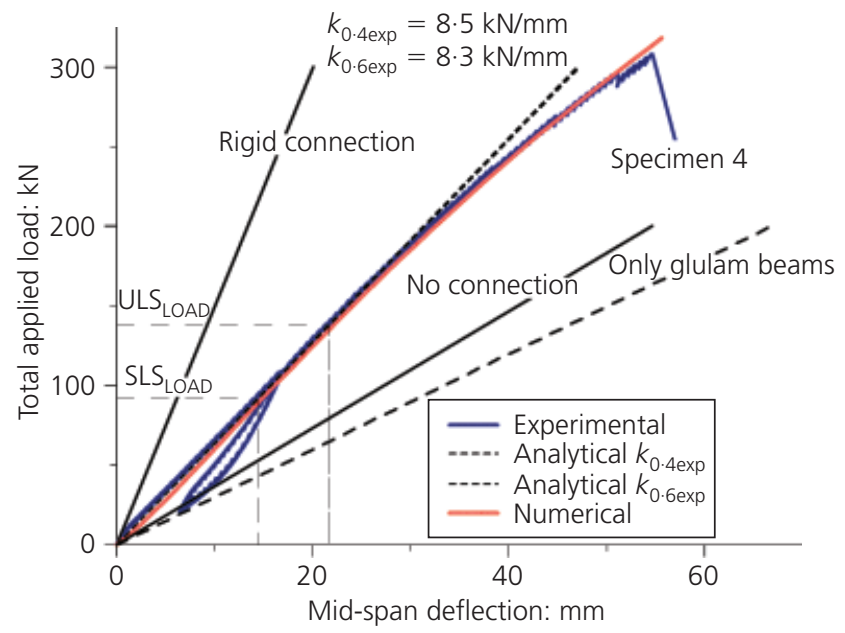

Figure 14. Load-mid-span deflection curve for connection type $\mathrm{SST}+\mathrm{S}^{*}$ (250 mm spacing) and corresponding numerical and analytical results, with limit case curves for fully rigid and fully flexible connections

comes of numerical analyses for specimen with $\mathrm{SST}+\mathrm{S}^{*}$ connectors spaced at $500 \mathrm{~mm} \mathrm{c} / \mathrm{c}$ and $\mathrm{ST}+\mathrm{S}+\mathrm{N}$ connectors spaced at $600 \mathrm{~mm} \mathrm{c/c}$ are presented in Figure 15. The figure clearly shows the better performance of the beam with $\mathrm{ST}+\mathrm{S}+\mathrm{N}$ connectors.

\subsection{Dynamic tests}

Frequency response functions, constructed using fast Fourier transforms of the recorded accelerations, indicate that the fundamental frequency $\left(f_{\mathrm{n}}^{\mathrm{I}}\right)$ for the specimen with $\mathrm{SST}+\mathrm{S}^{*}$ connectors was $18.9 \mathrm{~Hz}$ with a damping ratio $\zeta=7 \cdot 1 \%$; the second natural frequency $\left(f_{\mathrm{n}}^{\mathrm{II}}\right)$ was $25.8 \mathrm{~Hz}$ with a damping ratio $\zeta=7 \cdot 5 \%$. Similar results were obtained for the $\mathrm{SP}+\mathrm{N}^{*}$ connector type: $f_{\mathrm{n}}^{\mathrm{I}}=18.5 \mathrm{~Hz}(\zeta=7 \cdot 3 \%)$ and $f_{\mathrm{n}}^{\mathrm{II}}=24.8 \mathrm{~Hz}$ (damping ratio $\zeta=6.7 \%$ ). The fundamental frequencies indicate that the composite floor systems were well built from a dynamic response 


\begin{tabular}{|c|c|c|c|c|c|c|c|c|}
\hline \multirow{2}{*}{$\begin{array}{l}\text { Connector } \\
\text { type }\end{array}$} & \multirow{2}{*}{$\begin{array}{c}\text { Spacing } \\
\text { between } \\
\text { connectors: } \\
\text { mm }\end{array}$} & \multicolumn{2}{|c|}{ Experimental } & \multicolumn{2}{|c|}{ Numerical analysis } & \multirow{2}{*}{$\begin{array}{l}\text { Slip modulus, } \\
k_{0.4}: \mathrm{kN} / \mathrm{mm}\end{array}$} & \multicolumn{2}{|c|}{ Efficiency: \% } \\
\hline & & $\begin{array}{l}\text { Total load: } \\
\text { kN }\end{array}$ & $\begin{array}{l}\text { Max. } \\
\text { deflection: } \\
\text { mm }\end{array}$ & $\begin{array}{l}\text { Total load: } \\
\text { kN }\end{array}$ & $\begin{array}{l}\text { Max. } \\
\text { deflection: } \\
\text { mm }\end{array}$ & & SLS & ULS \\
\hline $\mathrm{SST}+\mathrm{S}^{*}$ & 250 & $\begin{array}{l}179 \cdot 1 \\
308 \cdot 2\end{array}$ & $\begin{array}{l}31 \cdot 4 \\
54 \cdot 5\end{array}$ & 318 & $55 \cdot 6$ & $8 \cdot 5$ & 57 & 56 \\
\hline $\mathrm{SST}+\mathrm{S}^{*}$ & 500 & $295 \cdot 9$ & $60 \cdot 9$ & 270 & $60 \cdot 2$ & $8 \cdot 5$ & 40 & 47 \\
\hline $\mathrm{ST}+\mathrm{S}+\mathrm{N}$ & 600 & - & - & 372 & $44 \cdot 4$ & $235 \cdot 7$ & 95 & 94 \\
\hline
\end{tabular}

Table 5. Experimental and numerical results of the tests to failure performed on specimens with SST $+\mathrm{S}^{*}$ connectors, and numerical results for composite beams with $\mathrm{ST}+\mathrm{S}+\mathrm{N}$ connectors

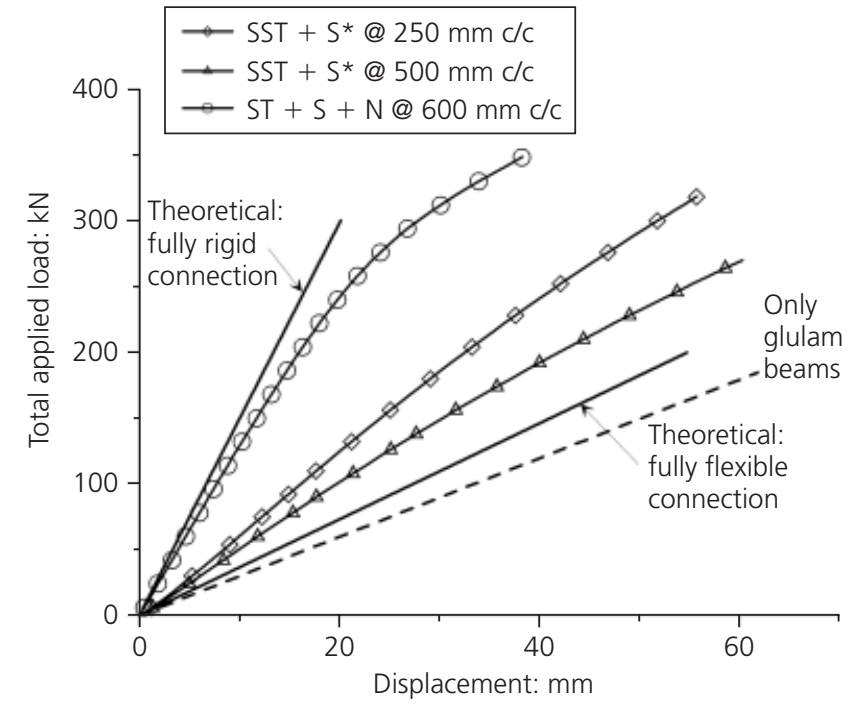

Figure 15. Numerical comparison of the performance in terms of load-mid-span deflection curves of composite beams with different connection systems

perspective, with natural first frequencies well above the value of $8 \mathrm{~Hz}$, below which the structure may become too susceptible to vibrations.

\subsection{Long-term bending}

The experimentally determined mid-span deflections for the specimen with $\mathrm{SST}+\mathrm{S}^{*}$ connector type are presented in Figure 16. The elastic deflection $v_{\text {el }}$ after applying the load was $5.4 \mathrm{~mm}$. The mid-span deflection then remained fairly constant until about 240 days after application of the load, when the environmental conditions changed rapidly and an increase in deflection was observed (Figure 16). At the end of the long-term test (339 days from the load application) but before the load was removed, the mid-span deflection $\left(v_{339,1}\right)$ was $9.5 \mathrm{~mm}$. A full description of the long-term test programme and results can be found in Lukaszewska et al. (2009).
Deflection after 50 years was analysed using a uniaxial FE model purposely developed for time-dependent behaviour of TCC beams (Fragiacomo, 2005) and was found to be $15.1 \mathrm{~mm}$ for specimens with SST $+\mathrm{S}^{*}$ connector types, corresponding to 2.8 times the instantaneous deflection (Lukaszewska, 2009). Eurocode 5 (CEN, 2003a) suggests limit values of $l / 250$ to $l / 200$ for long-term deflections of beams on two supports, $l$ being the span length. The deflection at the end of the service life was $l / 295$, which is less than the acceptable upper limit.

The beam with connector type $\mathrm{ST}+\mathrm{S}+\mathrm{N}$, which was not tested under long-term load, was also analysed using the FE model to predict its deflection at the end of a 50-year service life. All geometrical, mechanical and rheological properties of the glulam and concrete were assumed to be the same as those of the specimen with SST $+\mathrm{S}^{*}$ connector. The two concentrated live loads applied to the beam, estimated as the quasi-permanent part of the service load, were $9.26 \mathrm{kN}$. The final deflection was $10.8 \mathrm{~mm}$; this is $\sim 29 \%$ lower than for specimen with SST $+\mathrm{S}^{*}$ connector type, corresponding to $\sim 3.2$ times the elastic deflection. The final deflection value was $\sim 50 \%$ lower than the Eurocode 5 (CEN, 2003a) limit value of $l / 200$, showing excellent long-term performance (Lukaszewska, 2009).

\section{Conclusions}

An experimental programme including shear tests on small specimens, short-term bending and dynamic (impact) tests, and longterm tests on full-scale specimens $4.5 \mathrm{~m}$ long showed that prefabricated timber-concrete composite (TCC) structures perform satisfactorily under static and dynamic loading. The best results can be obtained using a notch connection reinforced with a coach screw, which was found to be far stiffer than the alternative configurations of only a coach screw or steel plates nailed to the timber. The aim to make entirely prefabricated drydry TCC systems significantly influenced the stiffness of shear connectors. For that reason, future research is needed to improve the stiffness of dry-dry shear connection systems. The deflection in the long term was less than the acceptable limits usually 


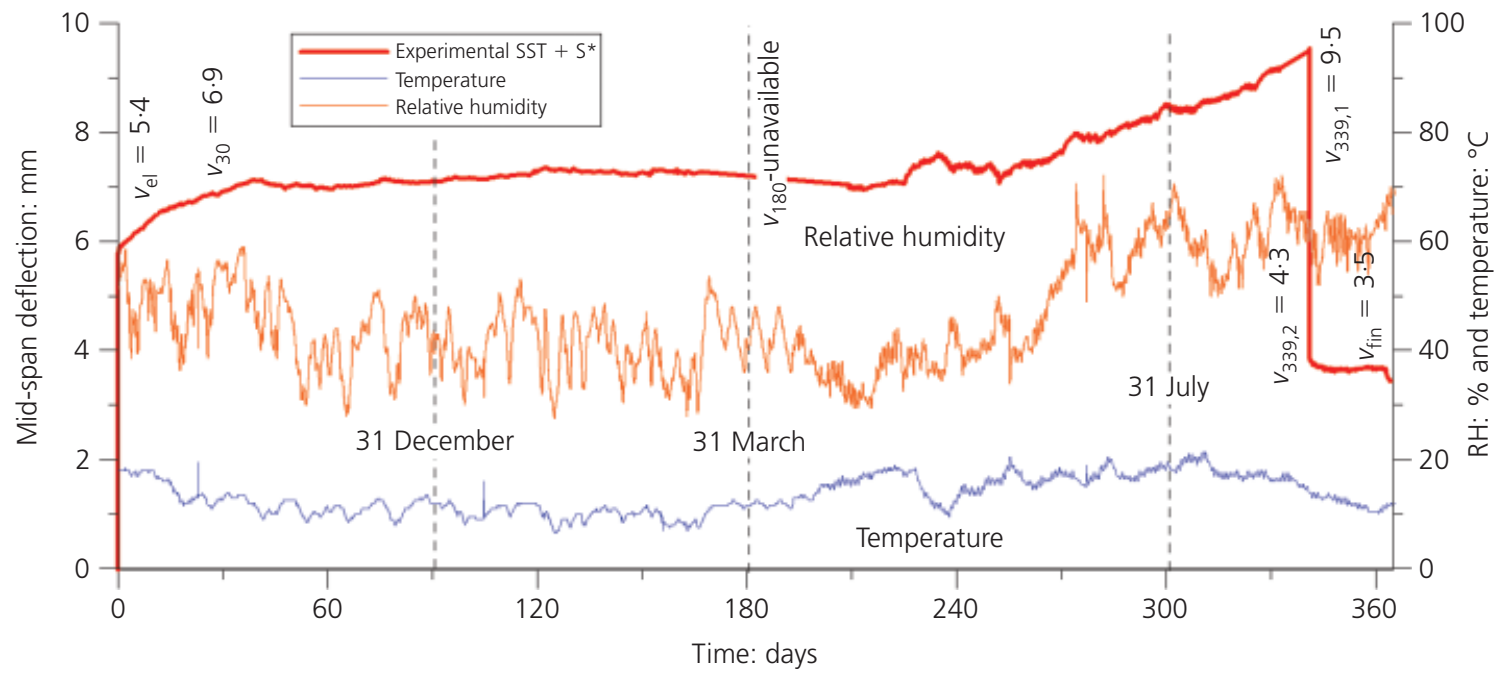

Figure 16. Trend in time of environmental conditions and mid-

span deflection for specimen with SST $+\mathrm{S}^{*}$ connectors in the

long-term test

suggested by current codes of practice. The natural frequency largely exceeded the value of $8 \mathrm{~Hz}$, proving that the system is not susceptible to vibrations if used for a $4.5 \mathrm{~m}$ span.

The design of TCC structures is a complex procedure, particularly when considering long-term overall structural performance. Primarily, it must be clearly stated that the structural behaviour of TCC members is mainly governed by the shear connection between timber and concrete. As the shear connection is usually characterised by a non-linear load-slip relationship, different values of slip moduli are adopted for SLS and ULS verifications. The slip modulus $k_{\text {ser }}$ for SLS is usually evaluated by means of push-out tests and corresponds to the secant value at $40 \%$ of the connection shear strength. The slip modulus $k_{\mathrm{u}}$ for ULS verifications should be assumed as the secant value at $60 \%$ of the connection shear strength. The mechanical properties (slip moduli and shear strength) of the most suitable connectors for prefabricated TCC beams were measured in experimental shear tests and are provided in the paper for design purposes.

From a practical perspective, joining concrete and timber through shear connectors embedded in prefabricated concrete slabs offers several advantages, including the following.

(a) Reduction of construction time since no time is needed for curing concrete on site.

(b) Avoidance of the use of 'wet' components during the generally 'dry' process of constructing timber buildings. No separating layer-foil (preventing timber from coming into contact with wet concrete) between the pre-cast concrete slab and timber, or formwork, which is often required during on-site processes in traditional timber-concrete systems, are needed.

(c) Realisation of the full stiffness of the TCC structure as soon as the concrete slab and timber beam are connected. This is in contrast to traditional wet systems, which require time to develop sufficient stiffness to sustain the full self-weight of the concrete slab.

(d) Shrinkage of concrete can freely occur when the concrete is allowed to cure in the prefabrication plant before assembly with the timber beam. This reduces subsequent stresses and deflections in the composite beam.

\section{REFERENCES}

Bathon L, Bletz O and Schmidt J (2006) Hurricane proof buildings - an innovative solution using prefabricated modular wood-concrete-composite elements. Proceedings of 9th World Conference on Timber Engineering WCTE 2006, Portland, Oregon, CD-Rom.

Blass HJ and Schlager M (1997) Connection for timber-concrete composite structures. International Conference on Composite Construction - Conventional and Innovative, Innsbruck.

Buchanan A, Deam B, Fragiacomo M, Pampanin S and Palermo A (2008) Multi-storey prestressed timber buildings in New Zealand. IABSE Structural Engineering International 18(2): 166-173.

Ceccotti A (1995) Timber-concrete composite structures. In Timber Engineering-STEP 2 (Blass HJ et al. (eds)). Centrum Hout, Almere, pp. E13/1-12.

Ceccotti A, Fragiacomo M and Gutkowski RM (2002) Design of timber-concrete composite structures according to EC5-2002 version. Proceedings of 35th Meeting of Working Commission W18 - Timber Structures, Kyoto, Japan. Karlsruhe Institute of Technology, Germany, paper 35-15-6.

Ceccotti A, Fragiacomo M and Giordano S (2006) Behaviour of a timber-concrete composite beam with glued connection at strength limit state. Proceedings of 9th World Conference on Timber Engineering WCTE 2006, Portland, Oregon, CD-Rom. Ceccotti A, Fragiacomo M and Giordano S (2007) Long-term and 
collapse tests on a timber-concrete composite beam with glued-in connection. Materials and Structures 40(1): 15-25.

CEN (European Committee for Standardization) (1991) EN 26891: Timber structures - joints made with mechanical fasteners. General principles for the determination of strength and deformation characteristics. CEN, Brussels.

CEN (2003a) Eurocode 5 EN 1995-1-1: Design of timber structures. Part 1-1: General rules and rules for buildings. CEN, Brussels.

CEN (2003b) Eurocode 5 EN 1995-2: Design of timber structures. Part 2: Bridges. CEN, Brussels.

Deam BL, Fragiacomo M and Buchanan AH (2008) Connections for composite concrete slab and LVL flooring systems. Materials and Structures 41(3): 495-507.

Fragiacomo M (2005) A finite element model for long-term analysis of timber-concrete composite beams. Structural Engineering and Mechanics 22(2): 173-189.

Fragiacomo M (2006) Long-term behaviour of timber-concrete composite beams. II: Numerical analysis and simplified evaluation. Journal of Structural Engineering 132(1): 23-33.

Fragiacomo M and Ceccotti A (2006a) Long-term behaviour of timber-concrete composite beams. I: Finite element modelling and validation. Journal of Structural Engineering 132(1): $13-22$.

Fragiacomo M and Ceccotti A (2006b) Simplified approach for the long-term behaviour of timber-concrete composite beams according to the Eurocode 5 provisions. Proceedings of 39th Meeting of Working Commission W18 - Timber Structures, Florence, Italy. Karlsruhe Institute of Technology, Germany, paper 39-9-1.

Fragiacomo M, Amadio C and Macorini L (2004) Finite-element model for collapse and long-term analysis of steel-concrete composite beams. Journal of Structural Engineering 130(3): 489-497.

Fragiacomo M, Amadio C and Macorini L (2007) Short- and long-term performance of the 'Tecnaria' stud connector for timber-concrete composite beams. Materials and Structures 40(10): 1013-1026.

Frangi A and Fontana M (2003) Elasto-plastic model for timberconcrete composite beams with ductile connection. IABSE Structural Engineering International 13(1): 47-57.

Gelfi E, Giuriani E and Marini A (2002) Stud shear connection design for composite concrete slab and wood beams. Journal of Structural Engineering 128(12): 1544-1550.

Gutkowski R, Brown K, Shigidi A and Natterer J (2008) Laboratory tests of composite wood-concrete beams. Construction and Building Materials 22(6): 1059-1066.

Kenel A (2000) Zur Berechnung von Holz/BetonVerbundkonstruktionen. Forschungs-bericht 115/42, EMPA, Abteilung Holz (in German).

Lukaszewska E (2009) Development of Prefabricated Timberconcrete Composite Floors. $\mathrm{PhD}$ thesis, Luleå University of Technology, Luleå, Sweden.

Lukaszewska E, Fragiacomo M and Frangi A (2007) Evaluation of the slip modulus for ultimate limit state verifications of timber-concrete composite structures. Proceedings of 40th Meeting of the Working Commission W18 - Timber Structures, Bled, Slovenia. Karlsruhe Institute of Technology, Germany, paper 40-7-5.

Lukaszewska E, Johnsson $\mathrm{H}$ and Fragiacomo M (2008) Performance of connections for prefabricated timberconcrete composite floors. Materials and Structures 41(9): $1533-1550$.

Lukaszewska E, Fragiacomo M and Johnsson H (2009) Timedependent behaviour of prefabricated timber-concrete composite floors. Engineering Structures under review.

Lukaszewska E, Fragiacomo M and Johnsson H (2010) Laboratory tests and numerical analyses of prefabricated timber-concrete composite floors. Journal of Structural Engineering 136(1): 46-55.

Möhler K (1956) Über das Tragverhalten von Biegerträgern und Druckstäben mit zusammengezetztgen Querschnitten und nachgiebigen Verbindungsmitteln. Habilitation, Technische Uiniversität Karlsruhe, Karlsruhe (in German).

Natterer J, Hamm J and Favre P (1996) Composite wood-concrete floors for multi-storey buildings. Proceedings of International Wood Engineering Conference, vol. 3, pp. 431-435.

Schänzlin J (2003) Zum Langzeitverhalten von Brettstapel-BetonVerbunddecken. $\mathrm{PhD}$ thesis, Institut für Konstruktion und Entwurf, University of Stuttgart (in German).

Schänzlin J and Kuhlmann U (2004) Time dependent behaviour of timber-concrete composite structures. Proceedings of 8 th World Conference on Timber Engineering, Lahti, Finland. pp. 313-318.

Toratti T and Kevarinmäki A (2001) Development of WoodConcrete Composite Floors. International Association for Bridge and Structural Engineering, Zurich, pp. 513-518.

Yeoh D, Fragiacomo M, Buchanan A and Gerber C (2009) A semi-prefabricated LVL-concrete composite floor system for the Australasian market. Australian Journal of Structural Engineering 9(3): 225-240.

Yeoh D, Fragiacomo M, De Franceschi M and Buchanan A (2010) Experimental tests of notched and plate connectors for LVLconcrete composite beams. Journal of Structural Engineering 137(2): 261-269.

\section{WHAT DO YOU THINK?}

To discuss this paper, please email up to 500 words to the editor at journals@ice.org.uk. Your contribution will be forwarded to the author(s) for a reply and, if considered appropriate by the editorial panel, will be published as a discussion in a future issue of the journal.

Proceedings journals rely entirely on contributions sent in by civil engineering professionals, academics and students. Papers should be $2000-5000$ words long (briefing papers should be 1000-2000 words long), with adequate illustrations and references. You can submit your paper online via www.icevirtuallibrary.com/content/journals, where you will also find detailed author guidelines. 